\title{
Impact of Socioeconomic Status on In-Hospital Outcome of Patients with Acute Coronary Syndrome in Egypt
}

\author{
Ahmed Hosny El-Adawy ${ }^{1, ~ *, ~ G h a d a ~ E l k h a w a g a ~}{ }^{2}$, Samir Abd Elraheem $^{1}$, Essam Mahfouz ${ }^{1}$ \\ ${ }^{1}$ Department of Cardiovascular Medicine, Faculty of Medicine, Mansoura University, Mansoura, Egypt \\ ${ }^{2}$ Department of Community Medicine, Faculty of Medicine, Mansoura University, Mansoura, Egypt
}

Email address:

dr_ahmed_hosny@msn.com (A. H. El-Adawy), ghadaelkhawaga@yahoo.com (G. Elkhawaga), samir.abdelraheem@yahoo.com (S. A. Elraheem), mahfouzessams@gmail.com (E. Mahfouz)

${ }^{*}$ Corresponding author

\section{To cite this article:}

Ahmed Hosny El-Adawy, Ghada Elkhawaga, Samir Abd Elraheem, Samir Abd Elraheem. Impact of Socioeconomic Status on In-Hospital Outcome of Patients with Acute Coronary Syndrome in Egypt. Clinical Medicine Research. Vol. 6, No. 6, 2017, pp. 164-172. doi: 10.11648/j.cmr.20170606.11

Received: September 15, 2017; Accepted: October 11, 2017; Published: November 20, 2017

\begin{abstract}
Cardiovascular problems are still the leading cause of deaths globally. Socioeconomic inequality continues to pose a challenge to health care suppliers and can greatly affect the clinical outcome of medical problems, especially in the cardiovascular field. This study aimed to assess the in-hospital outcome of patients with acute coronary syndrome admitted in the coronary care unit and to determine the relation between socioeconomic status (SES) and in-hospital outcome of acute coronary syndrome. A prospective observational study was conducted on 301 patients presented with acute coronary syndrome during the period from August 2015 to May 2016. A questionnaire was used to assess their socioeconomic status. Admitted patients with acute coronary syndrome (ACS) were classified into $31(10.3 \%)$ patients with non-ST segment elevation myocardial infarction (NSTEMI), 162 (53.8\%) with ST segment elevation myocardial infarction STEMI and 108 (35.9\%) with unstable angina (UA). According to patients SES, they were classified as 77 with high SES, 74 with middle SES, 84 with low SES, and 66 with very low SES. The study revealed that the lower socioeconomic status was statistically significant associated with increase of acute coronary syndrome mortality $(\mathrm{P}<0.001)$, the incidence of impaired left ventricular function, heart failure and stroke was associated. While, lower socioeconomic status was significantly associated decrease in the incidence of coronary angiography and percutaneous intervention. No significant change in the incidence of arrhythmia and major bleeding between socioeconomic status classes. Lower socioeconomic status in patients with acute coronary syndrome was considered as a risk factor for increased in-hospital mortality, stroke, impaired left ventricular function, and heart failure. To the best of author's knowledge, this study considered first report in Egypt discussing the in-hospital outcome of patients with ACS and to determine the relation between SES and in-hospital outcome of ACS patients.
\end{abstract}

Keywords: Acute Coronary Syndrome, Socioeconomic Status, In-Hospital Outcome

\section{Background}

Coronary heart disease (CHD) is a main cause of mortality and disability all over the world. Although its mortality rates have been declined over the past few decades, CHD accounts for about one-third or more of all deaths in individuals over 35 years [1]. In the United States, nearly one-half of middleaged men and one-third of middle-aged women will develop manifestation of acute coronary syndrome (ACS) which can be presented with unstable angina, non-ST segment elevation myocardial infarction (NSTEMI) or ST segment elevation (STEMI) [2].

Short term outcome (in-hospital or 30 days outcome) of patients with acute MI has been decreased over the past 30 years, concomitantly with the increasing use of reperfusion strategies and proven preventive therapies as beta blockers, aspirin and statins [3]. In a previous report evaluated in the period from 1987 to 2002 , the 28 day case fatality has been declined from 5.3 to $3.8 \%$ [4]. A similar trend was observed in analysis of data on 2.5 million patients from the American national registry of MI. in which in-hospital mortality after 
acute MI has been declined from $10.4 \%$ in 1994 to $6.3 \%$ in 2006 [5].

Beside death, other patient-main outcomes include stroke, heart failure and major bleeding. In the Global Registry of Acute Coronary Events (GRACE) of patients with non ST segment elevation ACS, the rates of in-hospital outcome heart failure or shock, MI, major bleeding or stroke were 10 , $2.4,1.8$ and $0.5 \%$, respectively [6].

Socioeconomic status (SES) can be defined as one's access to financial, social, cultural, and human capital resources. There are multiple approaches to measure SES. The most commonly used measures are education, occupational level and income. Each of these indicators measure various, closely related aspects of SES, and may be relevant to different health outcomes at different stages in life course [7]. Low SES associates not only with higher total mortality [8], but also with increased risk of CHD death [9].

Measuring SES is difficult and multifactorial. All conventional measures of SES have a clear gradient, paralleling health, but parts of effects of each these indicators are explained through the other indicators of SES [10].

This study aimed to assess the in-hospital outcome of acute coronary syndrome and to monitor the correlation between socioeconomic status and in-hospital outcome of acute coronary syndrome among those patients.

\section{Methods}

\subsection{Design and Subjects}

A prospective observational study was conducted during the period from August, 2015 to May, 2016 at coronary care unit, Mansoura Specialized Medical Hospital, Mansoura, Egypt. Three hundred and one patients presented with acute chest pain confirmed by Electrocardiogram (ECG) changes and or cardiac biomarkers elevations were admitted in the study.

Patients with atypical chest pain, not fulfill the criteria of ACS (chest pain, specific associated symptoms, abnormalities on ECG, and levels of serum markers of cardiac injury [11] and those who refused to participate in the study were excluded from the study.

\subsection{Sample Size Calculation}

A sample size used in the current study was calculated using online program with confidence level of $95 \%$ and a study power $80 \%$. Additional $10 \%$ was added to compensate for drop out cases.

\subsection{Case Definitions}

Among patients considered to have angina, there are three presentations of angina that suggest an ACS (rest angina which is usually more than 20 minutes in duration, new onset angina that markedly limits physical activity and increasing angina that is more frequent, longer in duration, or occurs with less exertion than previous angina).

Unstable angina (UA) and acute Non ST-segment elevation myocardial infarction (NSTEMI) differ primarily in whether the ischemia is severe enough to cause sufficient myocardial damage to release detectable quantities of a marker of myocardial injury (troponins).

Unstable angina (UA) is considered to be present in patients with ischemic symptoms suggestive of an ACS and no elevation in troponins, with or without electrocardiogram changes indicative of ischemia (ST segment depression or transient elevation or new $\mathrm{T}$ wave inversion).

Non ST-segment elevation myocardial infarction (NSTEMI) is considered to be present in patients having the same manifestations as those in UA, but in whom an elevation in troponins is detected.

Acute MI is defined as a clinical (or pathologic) event caused by myocardial ischemia in which there is evidence of myocardial injury or necrosis [12]. Criteria are met when there is a rise and /or fall of cardiac biomarkers, along with supportive evidence in the form of typical symptoms, suggestive ECG changes, or imaging evidence of new loss of viable myocardium or new regional wall motion abnormality.

\subsection{Measurement of Outcome Variables}

Mortality, stroke, heart failure, major bleeding, arrhythmia and impaired left ventricular dysfunction were measured in this study.

Mortality was measured in patients with ACS and died during first 30 days of his clinical presentation.

Stroke was defined in patients with ACS and has clinical manifestation of cerebral stroke (paralysis or loss of muscle movement, difficulty talking or swallowing, memory loss or thinking difficulties, emotional problems, pain, numbness or other strange sensations in parts of their bodies affected by stroke, changes in behavior and self-care ability) confirmed by cerebral C. T or MRI [13].

Patients with heart failure are those with ACS and has clinical manifestation of heart failure (dyspnea, paroxysmal nocturnal dyspnea, orthopnea, Cheyne-stoke respiration, cardiogenic shock) and his echo evaluation showed impaired ventricular systolic function [14].

Major bleeding defined as patient with ACS and has any clinically overt sign of hemorrhage that "is actionable" and requires diagnostic studies, hospitalization, or treatment by a health care professional, $\geq 5 \mathrm{gm} / \mathrm{dl}$ provided the hemoglobin drop is related to bleeding, cardiac tamponade, bleeding requiring surgical intervention for control (excluding dental/nasal/skin/hemorrhoid), bleeding requiring intravenous vasoactive drugs, intracranial hemorrhage and intraocular bleeding compromising vision [15].

Arrhythmia confined to the patient with ACS and his ECG showed either tachy-arrhythmia (SVT, A. F, atrial flutter, VT, VF) or brady-arrhythmia (sinus node dysfunction, HB) [16].

Patients with impaired left ventricular dysfunction are those with ACS with history of completely normal left ventricular function and on his new evaluation revealed impaired left ventricular function (ejection fraction below $40 \%$ ) [17]. 


\subsection{Clinical and Para-Clinical Measures}

The study was conducted in two phases for all investigated patients.

\subsubsection{Phase I}

\section{i. Questionnaire}

All participating patients were subjected to a predesigned questionnaire form about SES and were Followed up and evaluated for the outcome during the first month.

An interviewer-administered structured questionnaire focused on personal and socio-demographic data. Social class was assessed using the social scoring system developed by El-Gilany and Elkhawaga (2012) [18]. These criteria include age, sex, education, occupation, marital status, residence, income and housing status. It also included past medical and family history, clinical pattern of the attack: time of onset and presenting symptoms. According to patients SES, they were classified as 77 with high SES, 74 with middle SES, 84 with low SES, and 66 with very low SES.

Medical history, main management (investigations, treatment and period of stay in the hospital) and in-hospital outcome e.g. death, stroke, heart failure, arrhythmia, major bleeding, and impaired left ventricular function were reported. Chest pain was assessed according to Montalescot et al. (2013) [19] where patient with typical chest pain should meets the following three criteria (substernal chest pain or discomfort of characteristic quality and duration, or increase with exercise or emotional stress and or relieved with rest and/or nitroglycerine), patient with atypical chest pain which meets two criteria of the previous, patient with non-cardiac chest pain which meets one criterion or none of the above.

\section{ii. Past History of Risk Factors for CHD}

The other independent variables considered for this study included hypertension, smoking, diabetes mellitus (DM) and additional criteria included age, sex, risk factors and past medical history.

\section{iii. Clinical Examination}

All admitted patients were investigated general and cardiac examination (inspection and palpation for pericardial bulge, dilated veins, pulsations and thrills, auscultation for heart sounds, added sounds, murmurs and pericardial rub).

\section{iv. Laboratory Investigations}

The laboratory testes including complete blood count, serum creatinine, cardiac biomarkers (creatine kinase MB and troponin) and fasting blood sugar were performed.

\section{v. Electrocardiography}

Standard resting 12 leads ECG was done. Based on the main clinical, electrocardiography, and cardiac enzymes results, the studied patients were classified into UA group $(\mathrm{n}=108)$, NSTEMI group $(\mathrm{n}=31)$ and STEMI group $(\mathrm{n}=162)$.

\section{vi. Echocardiography}

To assess left ventricular function (ejection fraction, fractional shortening, regional systolic wall motion abnormalities) Echocardiography was performed.

\subsubsection{Phase II}

All admitted patients were followed up for 30 days considering hospital treatment (thrombolysis, anti-platelets, beta blockers, lipid lowering drugs, ACEs inhibitors or ARBs, anticoagulants, percutaneous intervention, CABG), duration from admission to reperfusion therapy, length of hospital stay (5 days, 6-10 days, 11-20 days, 21-30 days, 30 days), In- hospital outcome (death, stroke, major bleeding, arrhythmia, heart failure, impaired left ventricular function).

\subsection{Statistical Analysis}

Data were coded then analyzed using the computer program SPSS (Statistical package for social science) version 16. Qualitative data were described as numbers and percentages. The $\chi^{2}$ test or Monte Carlo test or Fisher's exact test was used for comparison between groups as appropriate. Quantitative data were described as means \pm (SD) after testing for normality by Kolmogorov-Smirnov test. One way ANOVA test was used for comparison between groups. Odds ratios and their $95 \%$ confidence interval were achieved.

\section{Results}

This study revealed statistical significant differences between studied groups regarding mean age, sex, residence, time from symptoms, mode of transport, smoking and history of myocardial infarction (Table 1).

Table 1. Socio-Demographic Characteristics and Medical History of Studied Patients.

\begin{tabular}{|c|c|c|c|c|}
\hline Criteria & NSTEMI $\mathrm{n}=\mathbf{3 1}$ & STEMI (MI) n=162 & UA $n=108$ & Significance \\
\hline \multicolumn{5}{|l|}{ Age } \\
\hline Mean \pm SD & $61.03 \pm 8.72$ & $57.45 \pm 10.27$ & $65.02 \pm 10.43$ & \multirow{2}{*}{$\mathrm{F}=2.95 ; \mathrm{P}=0.054$} \\
\hline Min-Max & $48.0-84.0$ & $21.0-84.0$ & $29.0-82.0$ & \\
\hline \multicolumn{5}{|l|}{ Sex } \\
\hline Male & $21(67.7)$ & $133(82.1)$ & $62(57.4)$ & \multirow{2}{*}{$x^{2}=19.7 ; p<0.001$} \\
\hline Female & $10(32.3)$ & $29(17.9)$ & $46(42.6)$ & \\
\hline \multicolumn{5}{|l|}{ Residence } \\
\hline rural & $13(41.9)$ & $75(46.3)$ & $54(50.0)$ & $x^{2}=0.73 ; p=0.701$ \\
\hline \multicolumn{5}{|l|}{ SES Classes } \\
\hline High & $8(25.8)$ & $46(28.4)$ & $23(21.3)$ & \multirow{4}{*}{$\mathrm{MC}^{*} ; \mathrm{P}=0.504$} \\
\hline Middle & $4(12.9)$ & $39(24.1)$ & $31(28.7)$ & \\
\hline Low & $12(38.7)$ & $43(26.5)$ & $29(26.9)$ & \\
\hline Very low & $7(22.6)$ & $34(21.0)$ & $25(23.1)$ & \\
\hline
\end{tabular}




\begin{tabular}{lllll}
\hline Criteria & NSTEMI $\mathbf{n}=\mathbf{3 1}$ & STEMI (MI) $\mathbf{n}=\mathbf{1 6 2}$ & UA n=108 & Significance \\
\hline Time from symptom & & & & \\
$<4 \mathrm{~h}$ & $25(80.6)$ & $132(81.5)$ & $95(88.0)$ & MC; $\mathrm{P}=0.117$ \\
$4-12 \mathrm{~h}$ & $4(12.9)$ & $18(11.1)$ & $12(11.1)$ & \\
$>12 \mathrm{~h}$ & $2(6.5)$ & $12(7.4)$ & $1(0.9)$ & \\
Mode of transport & & & & \\
Ambulance & $5(16.1)$ & $30(18.5)$ & $5(4.6)$ & $\mathrm{MC} ; \mathrm{P}=0.004$ \\
Taxi or private transport & $23(74.2)$ & $129(79.6)$ & $99(91.7)$ & \\
Public transport & $3(9.7)$ & $3(1.9)$ & $4(3.7)$ & $\mathrm{x}^{2}=18.34 ; \mathrm{p}<0.001$ \\
Smoking & $15(48.4)$ & $108(66.7)$ & $44(40.7)$ & $\mathrm{x}^{2}=2.77 ; \mathrm{p}=0.25$ \\
Known diabetic & $17(54.8)$ & $78(48.1)$ & $63(58.3)$ & $\mathrm{x}^{2}=2.65 ; \mathrm{p}=0.266$ \\
Known hypertensive & $22(71.0)$ & $101(62.3)$ & $77(71.3)$ & $\mathrm{x}^{2}=21.64 ; \mathrm{p}<0.001$ \\
History of myocardial infarction & $7(22.6)$ & $14(8.6)$ & $33(30.6)$ & $\mathrm{MC} ; \mathrm{p}=0.119$ \\
History of heart failure & $0(0.0)$ & $2(1.2)$ & $5(4.6)$ & \\
Chest pain ${ }^{*}$ & & & $108(100.0)$ & $\mathrm{MC} ; \mathrm{p}=0.07$ \\
Typical & $31(100.0)$ & $156(96.3)$ & $0(0.0)$ & \\
Atypical & $0(0.0)$ & $6(3.7)^{\mathrm{s}}$ & \\
\hline
\end{tabular}

*MC, Mote Carlo test.

\#All cases were presented with chest pain.

${ }^{\$} 6$ cases only with STEMI (MI) had atypical chest pain.

Moreover, statistical significant differences were seen among different ACS categories regarding mean systolic or diastolic blood pressure, thrombolysis, beta blockers, ACEs inhibitors, percutaneous intervention, duration of hospital stay, impaired left ventricular function, heart failure, arrhythmia and death as reported in table 2.

Table 2. Clinical Presentation, Management and in-Hospital Outcome of Studied Patients , .

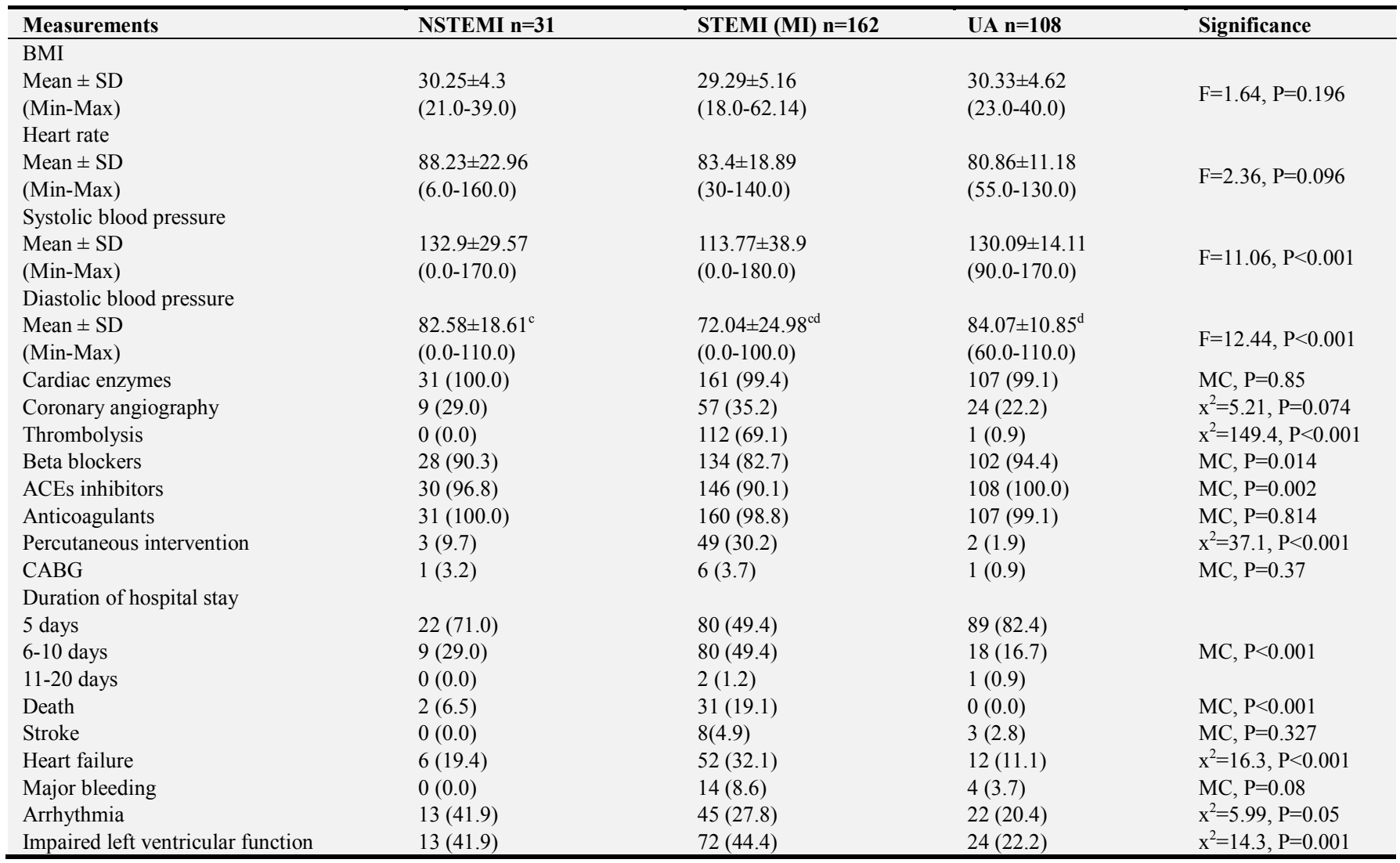

\# All patients were examined by ECG, received anti platelets and lipid lowering drugs.

$* \mathrm{MC}=$ Mote Carlo test.

There is significant increase in ACS mortality, incidence of stroke, incidence of impaired left ventricular function and incidence of heart failure as we go lower in SES classes $(\mathrm{P}<0.001)$. The results of the current study revealed a significant increase in ACS mortality as we go lower in the SES. It showed statistically significant association between SES and inhospital mortality ( $\mathrm{P}<0.001)$ (Table 3 ). 
Table 3. Complications Reported Among Patients with Different Socioeconomic Classes.

\begin{tabular}{|c|c|c|c|c|c|}
\hline \multirow{2}{*}{ Complication } & & \multicolumn{4}{|l|}{ SES Classes } \\
\hline & & Highn. (\%) & $\mathbf{P}(\mathbf{C I})$ & Middlen. (\%) & $\mathbf{P} /(\mathbf{C I})$ \\
\hline \multirow{2}{*}{ Death } & Yes & $4(12.1)$ & \multirow{2}{*}{1} & $4(12.1)$ & $\mathrm{P}=1$ \\
\hline & No & $73(27.2)$ & & $70(26.1)$ & $1.043(0.25-4.33)$ \\
\hline \multirow{2}{*}{ Stroke } & Yes & $1(9.1)$ & \multirow{2}{*}{1} & $2(18.2)$ & $\mathrm{P}=0.615$ \\
\hline & No & $76(26.2)$ & & $72(24.8)$ & $2.11(0.19-23.79)$ \\
\hline \multirow{2}{*}{ Impaired left ventricular function } & Yes & $13(11.9)$ & \multirow{2}{*}{1} & $22(20.2)$ & $\mathrm{P}=0.06$ \\
\hline & No & $64(33.3)$ & & $52(27.1)$ & $2.08(0.96-4.53)$ \\
\hline \multirow{2}{*}{ Heart failure } & Yes & $7(10.0)$ & \multirow{6}{*}{1} & $16(22.9)$ & $\mathrm{P}=0.032 *$ \\
\hline & No & $70(30.3)$ & & $58(25.1)$ & $2.76(1.063-1.33)$ \\
\hline \multirow{2}{*}{ Major bleeding } & Yes & $4(22.2)$ & & $3(16.7)$ & \\
\hline & No & $73(25.8)$ & & $71(25.1)$ & \\
\hline \multirow{2}{*}{ Arrhythmia } & Yes & $14(17.5)$ & & $22(27.5)$ & \\
\hline & No & $63(28.5)$ & & $52(23.5)$ & \\
\hline
\end{tabular}

Table 3. Continued.

\begin{tabular}{|c|c|c|c|c|c|c|}
\hline \multirow[b]{2}{*}{ Complication } & & \multicolumn{4}{|l|}{ SES Classes } & \multirow{2}{*}{ significance } \\
\hline & & Low n. (\%) & $\mathbf{P} /(\mathbf{C I})$ & Very low n. (\%) & $\mathbf{P} /(\mathbf{C I})$ & \\
\hline \multirow{2}{*}{ Death } & Yes & $9(27.3)$ & $\mathrm{P}=0.253$ & $16(48.5)$ & $\mathrm{P}=0.001 *$ & $\mathrm{MC}^{\#}$ \\
\hline & No & $75(28.0)$ & $2.19(0.646-7.43)$ & $50(18.7)$ & $5.84(1.84-18.5)$ & $\mathrm{P}=0.001$ \\
\hline \multirow{2}{*}{ Stroke } & Yes & $0(0.0)$ & $\mathrm{P}=0.478$ & $8(72.7)$ & $\mathrm{P}=0.012 *$ & $\mathrm{MC}^{\#}$ \\
\hline & No & $84(29.0)$ & $2.19(0.646-7.43)$ & $58(20.0)$ & $10.5(1.3-86.18)$ & $\mathrm{P}<0.001$ \\
\hline \multirow{2}{*}{ Impaired left ventricular function } & Yes & $39(35.8)$ & $\mathrm{P}<0.001 *$ & $35(32.1)$ & $\mathrm{P}<0.001$ * & $\chi^{2}=25.7$ \\
\hline & No & 45 (23.4) & $4.267(2.05-8.9)$ & $31(16.1)$ & $5.56(2.58-11.98)$ & $\mathrm{P}<0.001$ \\
\hline \multirow{2}{*}{ Heart failure } & Yes & $22(31.4)$ & $\mathrm{P}=0.005^{*}$ & $25(35.7)$ & $\mathrm{P}=0.005^{*}$ & $\chi^{2}=17.08$ \\
\hline & No & $62(26.8)$ & $3.55(1.42-8.87)$ & $41(17.7)$ & $3.55(1.42-8.87)$ & $\mathrm{P}=0.001$ \\
\hline \multirow{2}{*}{ Major bleeding } & Yes & $5(27.8)$ & & $6(33.3)$ & & $\mathrm{MC}^{\#}$ \\
\hline & No & 79 (27.9) & & $60(21.2)$ & & $\mathrm{P}=0.657$ \\
\hline \multirow{2}{*}{ Arrhythmia } & Yes & $25(31.2)$ & & $19(23.8)$ & & $\chi 2=3.76$ \\
\hline & No & $59(26.7)$ & & $47(21.3)$ & & $\mathrm{P}=0.289$ \\
\hline
\end{tabular}

"MC: Monte Carlo test.

There is no significant change in the incidence of major bleeding and arrhythmia between SES classes. Statistical significant differences in time from symptom onset until arrival to hospital, in performing coronary angiography and percutaneous intervention between SES classes, $(\mathrm{P}<0.001)$ as illustrated in table 4.

Table 4. Management Among Different Socioeconomic Classes.

\begin{tabular}{|c|c|c|c|c|c|c|}
\hline \multirow{2}{*}{ Management } & & \multicolumn{4}{|l|}{ SES Classes } & \multirow{2}{*}{ significance } \\
\hline & & High n (\%) & Middle n (\%) & Low n (\%) & Very low n (\%) & \\
\hline \multirow{3}{*}{ Time from symptom } & $<4 \mathrm{~h}$ & $77(30.6)$ & $69(27.4)$ & $71(28.2)$ & $35(13.9)$ & \multirow{3}{*}{$\begin{array}{l}\mathrm{MC}^{\#} \\
\mathrm{P}=0.001\end{array}$} \\
\hline & $4-12 \mathrm{~h}$ & $0(0.0)$ & $3(8.8)$ & $10(29.4)$ & $21(61.8)$ & \\
\hline & $>12 \mathrm{~h}$ & $0(0.0)$ & $2(13.3)$ & $3(20.0)$ & $10(66.7)$ & \\
\hline \multirow{2}{*}{ Coronary angiography } & Yes & $35(61.4)$ & $14(24.6)$ & $4(7.0)$ & $4(7.0)$ & $\mathrm{MC}^{\#}$ \\
\hline & No & $11(10.5)$ & $25(23.8)$ & $39(37.1)$ & $30(28.6)$ & $\mathrm{P}<0.001$ \\
\hline Percutaneus intervention & No & $12(10.6)$ & $30(26.5)$ & $37(32.7)$ & $34(30.1)$ & $\mathrm{P}<0.001$ \\
\hline
\end{tabular}

${ }^{\#}$ MC: Monte Carlo test Discussion.

Cardiovascular diseases are still the leading cause of mortality all over the world not only in developed countries [20] and in many developing countries including Egypt. Although, There is a positive relation between SES and health in developed countries [21], only a few studies have examined this association in non-developed countries including South Africa countries [22]. Ischemic heart diseases mortalities have been decreased over the $8^{\text {th }}$ decade of the previous century, this decrease in mortality rate differ between lower and higher SES classes [23].

Regarding cardiovascular risk factors and cardiac disorders, many studies have shown that a lower socioeconomic status (SES) is commonly associated with them [24]. But few studies mentioned important association between SES and IHD mortality [25] and others mentioned no or weak associations [26].

SES is a complex phenomenon depends on a wide variety of variables that is often a combination of financial, occupational, and educational impacts [27]. To assess patient's SES, the most commonly used indicators are income, education, and occupation. Each of these indicators measure various, often closely related aspects of SES, and may be relevant to different health outcomes at different stages in life course [7]. 
Acute coronary syndromes (ACS) can be presented with unstable angina (UA), acute NSTEMI, and acute STEMI. The main in-hospital outcome of acute coronary syndrome includes death, stroke, major bleeding, arrhythmia, and heart failure [6].

The current prospective observational study was carried on 301 patients presented with acute chest pain and confirmed diagnosis of ACS based on ECG changes and or cardiac enzymes elevation in order to assess the in-hospital outcome of acute coronary syndrome and to monitor the correlation between socioeconomic status and in-hospital outcome of acute coronary syndrome among those patients. All participating patients were subjected to a predesigned questionnaire form about SES, findings of medical examination and investigations were performed and patients were Followed up and evaluated for the outcome during the first month.

Admitted patients with acute coronary syndrome were classified into $31(10.3 \%)$ patients with NSTEMI, 162 $(53.8 \%)$ with STEMI and 108 (35.9\%) with unstable angina (UA). According to patients SES, they were classified as 77 with high SES, 74 with middle SES, 84 with low SES, and 66 with very low SES.

The results of this study revealed a significant increase in ACS mortality as we go lower in the SES. The association between SES and in-hospital mortality was statistically significant $(\mathrm{P}<0.001)$. This unique relation between specific mortality of a disease and SES is well documented in developed countries [21], but this relation is not well documented in less developed countries including Egypt [22].

Other studies was carried out by Welch et al. on 84423 patients in England revealed association between in-hospital mortality of ACS and SES as patient go lower in SES, increased risk of mortality. [28]. A previous study performed by Hutchings et al. on 51572 patients show the same relation and referred this to that: patients with lower SES received lower quality of treatment [29]. In contrast, the study conducted by Ciccone et al. on 49949 patients in Italy showed no relation between ACS in-hospital mortality and SES when managed under optimum conditions [30]. Moreover, another study carried in Canada by Pilote et al. on 145882 patients revealed also a negative relation either in short term or long term mortality [31].

In this study there is a statistically significant change between SES classes and time from onset of symptoms until patients arrived to the hospital and seek medical care. This appear when many patients with low SES take a long time from beginning of chest pain until they seek medical advice ( about $66 \%$ of patients who wait more than 12 hours from symptom onset until arrival to hospital were of very low SES). However, in this study, all patients with high SES seek medical advice in less than 4 hours. The 2013 American College of Cardiology Foundation/American Heart Association guidelines for management of acute STEMI recommend early recognition and administration of reperfusion therapy since the beneficial effects of therapy with reperfusion agents are greatest when performed soon after presentation [32]. This apparent that in the term which states that: "time is muscle".

This delayed presentation to treatment can explain the higher mortality in the very low SES class.

Other studies revealed that a higher risk of mortality has been associated with lower SES in the setting of ACS [33]. This is because of obstacles to in-time medical care and settled appropriate interventions [34]. Numerous studies have shown SES-related differences in the employment of appropriate therapies such as invasive cardiac procedures [35].

This study showed significant statistically change of SES in the prevalence of coronary angiography and PCI. Current results clearly revealed that significant decrease in the incidence of coronary angiography and PCI as we go lower in SES classes $(\mathrm{P}<0.001)$. This decrease in the use of coronary angiography and PCI may also explain the higher mortality and morbidity in very low SES class.

Previous study showed that lower SES has been associated with lower rate of PCI [36], longer suspense for the procedure, and less recover in quality of life after PCI compared to higher SES [37].

The current study results also revealed a statistically significant change between SES in the prevalence of impaired left ventricular function assessed by echocardiography, heart failure, and stroke. Meanwhile, it showed no statistically significant change between SES in the prevalence of major bleeding or arrhythmia. This in agreement with previous studies which explain the relation between SES and heart failure also document as the patient go lower in the SES, he will be at increased risk of developing heart failure following attack of ACS. This increase in heart failure with the decrease in SES was confirmed in the meta-analysis of Hawkins et al., 2012 who found that socioeconomic depravation is a powerful independent predictor of heart failure development and adverse outcomes after ACS [38].

To explain the increased incidence of impaired left ventricular function assessed by echocardiography and heart failure among those with very low and low SES and decreased this prevalence among those with high SES, it is important to notice that the most common causes of systolic dysfunction are coronary (ischemic) heart diseases and that effective therapy of it lead to reduction in the rate of heart failure [39]. This effective therapy is mostly applied to patients with high SES in contrast to those with lower classes who presented late and receive less effective treatment.

For increased incidence of stroke in lower SES and decreased its incidence in high SES classes, there are probably some reasons. One of them is probably the general condition of the patient and associated co-morbidities. It is most probable that people with lower financial resources and who don't work tend to have less healthy food and those with lower education have less knowledge about what exactly constitutes a healthy lifestyle and diet. According to Keeley et al., 2003, if high-quality PCI is available, multiple 
randomized trials have shown enhanced survival and a lower rate of intracranial hemorrhage and recurrent MI compared to fibrinolysis [40].

The possible causes that arrhythmia in the current study wasn't affected by SES is possibly that the mechanism of arrhythmia following ACS is the damaged myocardium, which produces a substrate capable of developing reentrant circuits or associated with enhanced automaticity [41], and modulating factors, such as electrolyte imbalance (hypokalemia), dysfunction of the autonomic nervous system (increased sympathetic activity), continued ischemia and elevated plasma levels of free fatty acids. These factors may act on both substrate and triggers to induce arrhythmias [42]. These two mechanisms are not modified by SES class of the patient.

Also, in this study results, the possible cause that major bleeding wasn't affected by SES is possibly that all patients with ACS were managed in the same manner with antiplatelets, thrombolysis, and anticoagulants. These agents increase the risk of major bleeding. Another possible cause is that other associated co-morbidities like liver cirrhosis and esophageal varices. These co-morbidities do not change with SES.

\section{Conclusions}

Socioeconomic status didn't affect the type of presentation of ACS. Short- term mortality of ACS is increased as we go lower in the SES which is associated with longer time from presentation to hospital management and management of chest pain. Lower SES was also associated with high prevalence of impaired left ventricular function, heart failure, stroke, and lower rate of coronary angiography and PCI. There was no relation between SES and prevalence of arrhythmia and major bleeding.

Study Strengths, limitations and recommendations.

To the best of author's knowledge, this is the first registry data to assess the association between SES indicators and the in-hospital mortality of ACS patients in Egypt. While most of the evidence for socioeconomic inequalities in health come from western countries and USA. All the data in this study were recorded by well-trained physicians and the validity of the data were further checked. Nevertheless, the study has some limitations. The principal limitations of this study are related to its relatively small sample size and also to the measurement of SES which is to some extent were subjective as it depended on the patient educational level, mentality and social behavior. Optimum medical management should be the same for all patients with ACS regardless their SES. There should be medical awareness about ACS and the importance of its early recognition and management to the public especially those with low SES.

\section{Ethical Statement}

Study protocol was approved by Medical Ethics research Committee of the faculty of medicine, Mansoura University,
Egypt and from the mangers of the hospital in which the study was conducted. Informed written consent was obtained from each participant in the study. Confidentiality and personal privacy was respected in all levels of the study. Collected data will not be used for any other purpose.

\section{Funding}

The research received no grant from any funding agency in the public, commercial or not-for-profit sectors.

\section{Conflict of Interest}

The authors declare that they have no competing interests.

\section{References}

[1] Nichols M, Townsend N, Scarborough P, Rayner M. Cardiovascular disease in Europe 2014: epidemiological update. European heart journal. 2014:ehu299.

[2] Siegerink B, Maas R, Vossen CY, Schwedhelm E, Koenig W, Böger R, et al. Asymmetric and symmetric dimethylarginine and risk of secondary cardiovascular disease events and mortality in patients with stable coronary heart disease: the KAROLA follow-up study. Clinical Research in Cardiology. 2013;102:193-202.

[3] Velagaleti RS, Pencina MJ, Murabito JM, Wang TJ, Parikh NI, $\mathrm{D}^{\prime}$ Agostino RB, et al. Long-term trends in the incidence of heart failure after myocardial infarction. Circulation. 2008;118:2057-62.

[4] Myerson M, Coady S, Taylor H, Rosamond WD, Goff DC, investigators A. Declining Severity of Myocardial Infarction From 1987 to 2002 The Atherosclerosis Risk in Communities (ARIC) Study. Circulation. 2009;119:503-14.

[5] Rogers WJ, Frederick PD, Stoehr E, Canto JG, Ornato JP, Gibson CM, et al. Trends in presenting characteristics and hospital mortality among patients with ST elevation and nonST elevation myocardial infarction in the National Registry of Myocardial Infarction from 1990 to 2006. American heart journal. 2008;156:1026-34.

[6] Brieger D, Fox KA, FitzGerald G, Eagle KA, Budaj A, Avezum A, et al. Predicting freedom from clinical events in non-ST-elevation acute coronary syndromes: the Global Registry of Acute Coronary Events. Heart. 2009;95:888-94.

[7] Galobardes B, Shaw M, Lawlor DA, Lynch JW, Smith GD. Indicators of socioeconomic position (part 1). Journal of epidemiology and community health. 2006;60:7-12.

[8] Stringhini S, Sabia S, Shipley M, Brunner E, Nabi H, Kivimaki M, et al. Association of socioeconomic position with health behaviors and mortality. Jama. 2010;303:1159-66.

[9] Avendano M, Kunst AE, Huisman M, Lenthe FV, Bopp M, Regidor E, et al. Socioeconomic status and ischaemic heart disease mortality in 10 western European populations during the 1990s. Heart. 2006;92:461-7.

[10] Lammintausta A. Effects of Socioeconomic Status and Sociodemographic Features on Cardiovascular Disease. Mortality and Morbidity in Finland. 2013. 
[11] Boersma E, Pieper KS, Steyerberg EW, Wilcox RG, Chang $\mathrm{W}-\mathrm{C}$, Lee KL, et al. Predictors of outcome in patients with acute coronary syndromes without persistent ST-segment elevation results from an international trial of 9461 patients. Circulation. 2000;101:2557-67.

[12] Thygesen K, Alpert JS, Jaffe AS, Simoons ML, Chaitman BR, White HD. Third universal definition of myocardial infarction. Circulation. 2012;126:2020-35.

[13] Schwamm LH, Ali SF, Reeves MJ, Smith EE, Saver JL, Messe S, et al. Temporal trends in patient characteristics and treatment with intravenous thrombolysis among acute ischemic stroke patients at Get With The Guidelines-Stroke hospitals. Circulation: Cardiovascular Quality and Outcomes. 2013;6:543-9.

[14] Yancy CW, Jessup M, Bozkurt B, Butler J, Casey DE, Drazner $\mathrm{MH}$, et al. $2013 \mathrm{ACCF} / \mathrm{AHA}$ guideline for the management of heart failure: a report of the American College of Cardiology Foundation/American Heart Association Task Force on Practice Guidelines. Journal of the American College of Cardiology. 2013;62:e147-e239.

[15] Mehran R, Rao SV, Bhatt DL, Gibson CM, Caixeta A, Eikelboom J, et al. Standardized bleeding definitions for cardiovascular clinical trials a consensus report from the bleeding academic research consortium. Circulation. 2011;123:2736-47.

[16] Das B, Mishra TK. Prevention and Management of Arrhythmias in Acute Myocardial Infarction. International Journal of Contemporary Medical Research.

[17] Lang RM, Badano LP, Mor-Avi V, Afilalo J, Armstrong A, Ernande L, et al. Recommendations for cardiac chamber quantification by echocardiography in adults: an update from the American Society of Echocardiography and the European Association of Cardiovascular Imaging. Journal of the American Society of Echocardiography. 2015;28:1-39. e14.

[18] El-Gilany A, Elkhawaga G. Socioeconomic determinants of eating pattern of adolescent students in Mansoura, Egypt. The Pan African Medical Journal. 2012;13:22.

[19] Montalescot G, Sechtem U, Achenbach S, Andreotti F, Arden C, Budaj A, et al. 2013 ESC guidelines on the management of stable coronary artery disease. European heart journal. 2013;34:2949-3003.

[20] Stirbu I, Looman C, Nijhof GJ, Reulings PG, Mackenbach JP. Income inequalities in case death of ischaemic heart disease in the Netherlands: a national record-linked study. Journal of epidemiology and community health. 2012;66:1159-66.

[21] Mansyur C, Amick BC, Harrist RB, Franzini L. Social capital, income inequality, and self-rated health in 45 countries. Social science \& medicine. 2008;66:43-56.

[22] Case A. Does money protect health status? Evidence from South African pensions. Perspectives on the Economics of Aging: University of Chicago Press; 2004. p. 287-312.

[23] Davies CA, Dundas R, Leyland AH. Increasing socioeconomic inequalities in first acute myocardial infarction in Scotland, 1990-92 and 2000-02. BMC Public Health. 2009;9:1

[24] Ljung R, Peterson S, Hallqvist J, Heimerson I, Diderichsen F. Socioeconomic differences in the burden of disease in Sweden. Bulletin of the World Health Organization.

\section{$2005 ; 83: 92-9$}

[25] Gerber Y, Benyamini Y, Goldbourt U, Drory Y, Infarction ISGoFAM. Neighborhood socioeconomic context and longterm survival after myocardial infarction. Circulation. 2010;121:375-83.

[26] Danchin N, Neumann A, Tuppin P, De Peretti C, Weill A, Ricordeau P, et al. Impact of Free Universal Medical Coverage on Medical Care and Outcomes in Low-Income Patients Hospitalized for Acute Myocardial Infarction An Analysis From the French National Health Insurance System. Circulation: Cardiovascular Quality and Outcomes. 2011;4:619-25.

[27] Winkleby MA, Jatulis DE, Frank E, Fortmann SP. Socioeconomic status and health: how education, income, and occupation contribute to risk factors for cardiovascular disease. American journal of public health. 1992;82:816-20.

[28] Welch CA, Harrison DA, Hutchings A, Rowan K. The association between deprivation and hospital mortality for admissions to critical care units in England. Journal of critical care. 2010;25:382-90.

[29] Hutchings A, Raine R, Brady A, Wildman M, Rowan K. Socioeconomic status and outcome from intensive care in England and Wales. Medical care. 2004;42:943-51.

[30] Ciccone G, Lorenzoni L, Ivaldi C, Ciccarelli E, Piobbici M, Arione R. [Social class, mode of admission, severity of illness and hospital mortality: an analysis with" All patient refined DRG" of discharges from the Molinette hospital in Turin]. Epidemiologia e prevenzione. 1998;23:188-96.

[31] Pilote L, Tu JV, Humphries K, Behouli H, Belisle P, Austin $\mathrm{PC}$, et al. Socioeconomic status, access to health care, and outcomes after acute myocardial infarction in Canada's universal health care system. Medical care. 2007;45:638-46.

[32] O'Gara PT, Kushner F, Ascheim D. ACCF/AHA Guideline. Circulation. 2013;127:529-55.

[33] Fabreau GE, Leung AA, Southern DA, Knudtson ML, McWilliams JM, Ayanian JZ, et al. Sex, socioeconomic status, access to cardiac catheterization, and outcomes for acute coronary syndromes in the context of universal healthcare coverage. Circulation: Cardiovascular Quality and Outcomes. 2014;7:540-9.

[34] Smolderen KG, Spertus JA, Nallamothu BK, Krumholz HM, Tang F, Ross JS, et al. Health care insurance, financial concerns in accessing care, and delays to hospital presentation in acute myocardial infarction. Jama. 2010;303:1392-400.

[35] Chang W-C, Kaul P, Westerhout CM, Graham MM, Armstrong PW. Effects of socioeconomic status on mortality after acute myocardial infarction. The American journal of medicine. 2007;120:33-9.

[36] Livesey S. Socio-economic deprivation and outcome in patients with coronary artery disease. Heart. 2009;95:785-6.

[37] Leyland AH, Dundas R, McLoone P, Boddy FA. Causespecific inequalities in mortality in Scotland: two decades of change. A population-based study. BMC Public Health. 2007;7:1.

[38] Hawkins NM, Jhund PS, McMurray JJ, Capewell S. Heart failure and socioeconomic status: accumulating evidence of inequality. European journal of heart failure. 2012;14:138-46. 
[39] He J, Ogden LG, Bazzano LA, Vupputuri S, Loria C, Whelton PK. Risk factors for congestive heart failure in US men and women: NHANES I epidemiologic follow-up study. Archives of internal medicine. 2001;161:996-1002.

[40] Keeley E, Boura J, Grines C. Primary angioplasty versus intravenous thrombolytic therapy for acute myocardial infarction: a quantitative review of 23 randomised trials. Lancet. 2003;361:13-20.
[41] Popović AD, Nesković A, Pavlovski K, Marinković J, Babić $\mathrm{R}$, Bojić M, et al. Association of ventricular arrhythmias with left ventricular remodelling after myocardial infarction. Heart. 1997;77:423-7.

[42] Tansey M, Opie L. Relation between plasma free fatty acids and arrhythmias within the first twelve hours of acute myocardial infarction. The Lancet. 1983;322:419-22. 